\title{
Serum Caspase- 3 and Caspase- 7 as Predictive Factors of Response in Locally Advanced and Metastatic Breast Carcinoma
}

\author{
Hayma Hammoud' ${ }^{1}$ Jumana Saleh1, Marroan Bachour ${ }^{2}$, Maher Salamoon ${ }^{2 *}$ \\ ${ }^{1}$ Faculty of Pharmacy, Damascus University, Damascus, Syria \\ ${ }^{2}$ Department of Medical Oncology, Al Bairouni University Hospital, Damascus, Syria \\ Email: ${ }^{*}$ maheroncology@yahoo.com
}

Received 31 March 2014; revised 1 May 2014; accepted 8 May 2014

Copyright (C) 2014 by authors and Scientific Research Publishing Inc. This work is licensed under the Creative Commons Attribution International License (CC BY). http://creativecommons.org/licenses/by/4.0/

(c) (i) Open Access

\section{Abstract}

Introduction: Breast cancer is the most common cancer in women and the second most frequent cause of cancer death. Several factors affect response to chemotherapy including nodal status, hormonal status and human epidermal growth factor receptor (Her-2). Aim of Study: The study is aiming at evaluating Caspase-3, 7 levels in serum of patients with locally advanced and metastatic breast cancer and establishing the relation between Casepase level and response to chemotherapy. Patients and Methods: The study was performed at Al Bairouni University Hospital and the Faculty of Pharmacy (Damascus-Syria). We have included 60 patients with histologic confirmation of invasive ductal carcinoma of the breast treated with the combination (Docetaxel + Doxorubicin) with Caspase-3, 7 levels to be evaluated before treatment and 24 hours after the first and third cycle. Results: Caspase- 3 level increases in serum 24 hours after the $1^{\text {st }}$ cycle correlated with different kinds of response in 39 patients $(P$ value 0.0002$)$ with better results in those with Estrogen Receptors (ER) positive patients ( $P$ 0.005). In a similar manner, Caspase-7 level increases 24 hours after the $1^{\text {st }}$ cycle correlated with response in 40 patients $(P$ 0.005). However, ER status had no impact on response in Caspase-7 group ( $P$ 0.2). Conclusion: Caspase-3 and 7 levels in serum are useful as a predictive marker of response to chemotherapy in both locally advanced and metastatic breast cancer especially when tittered 24 hours after the first chemotherapy.

\section{Keywords}

Caspase-3, 7, Metastatic Breast Cancer, Response

\footnotetext{
${ }^{*}$ Corresponding author.
}

How to cite this paper: Hammoud, H., et al. (2014) Serum Caspase-3 and Caspase-7 as Predictive Factors of Response in Locally Advanced and Metastatic Breast Carcinoma. Journal of Cancer Therapy, 5, 584-590. 


\section{Introduction}

In the United States, breast cancer remains the most common cancer in women and the second most frequent cause of cancer death [1]. There are a number of factors which determine the prognosis of disease and response to treatment. Prognostic factors are those which determine the outcome of disease in the absence of systemic treatment whereas predictive factors predict response to treatment [1]. Estrogen receptor (ER) and progesterone receptor (PR) expression are the most important and useful predictive factors currently available. ER and PR are intracellular steroid hormone receptors which have received substantial attention since 1986. Measurable amounts of ER and PR are found in about 50\% - 85\% of patients with breast cancer. The frequency of positivity and the level of ER and PR increase with age, reaching their highest levels in postmenopausal women [2]. Apoptosis (programmed cell death) plays an important role in tissue homeostasis and development. It is regulated by a wide variety of survival signals as well as cellular mechanisms that are in charge of DNA integrity [3]. The apoptosis execution mechanism results in the development of characteristic morphological features such as nucleus and chromatin condensation, cell shrinkage and cytoplasmic blebs. The measure for quantification of apoptosis is the apoptotic index (AI). Many publications have proved that breast cancers with a high apoptosis index (programmed cell death) have a better prognosis compared with the same type of cancer with less or no apoptosis [4].

Although multiple genes are involved in apoptosis, the key mediators of the process are the Caspases. Caspases are Aspartate-specific Cysteine proteases, which cleave their substrates on the carboxyl side of the Aspartate residue [5] [6]. Currently at least 14 different Caspases are known to exist, of which two thirds play a role in apoptosis. The Caspases involved in apoptosis can be divided into two main groups, the initiator Caspases (e.g., Caspases 8, 9, and 10) and the downstream effector Caspases (e.g., Caspases 2, 3, 6, and 7). It is the members of the latter group that degrade multiple cell proteins and are responsible for the morphological changes in apoptosis. Caspase-3 is the most widely studied of the effector Caspases. It plays a key role in both the death receptor pathway, initiated by Caspase-8, and the mitochondrial pathway, involving Caspase-9. In addition, several studies have shown that Caspase-3 activation is required for apoptosis induction in response to chemotherapeutic drugs e.g., Taxanes, 5-fluorouracil, and doxorubicin [7]-[10]. Some studies investigated Caspases and their role in breast cancer, some of which studied Caspase levels and expression in breast carcinoma at mRNA level, however, little work has been made to evaluate levels of Caspases in serum of patients under treatment, therefore, the aim of this study is to titer the concentration of both Caspase-3 and 7 in serum of patients with locally advanced and metastatic breast cancer, then to evaluate the relation between Caspase concentration (fold increase) and response to chemotherapy.

\section{Patients and Methods}

\subsection{Patients}

The study is prospective, initiated in September 2012 and included 102 persons (21 disease free patients on follow up, 21 healthy volunteers and 60 patients diagnosed with locally advanced and metastatic invasive ductal carcinoma of the breast). 25 patients presented with hepatic metastasis, 22 with pulmonary metastasis, 3 with bone metastasis and 10 others with locally advanced disease as illustrated in Table 1. Age of patients was between 28 and 62 years (51 years in median), good performance status (0,1 and 2), normal hepatic and renal functions and pathologic confirmation of disease. The study was performed at the Breast cancer unit (al Bairouni university cancer center) and the faculty of Pharmacy Labs in Damascus (SYRIA). Both locally advanced and metastatic group received the same combination chemotherapy (Docetaxel $75 \mathrm{mg} / \mathrm{m}^{2}$ and Doxorubicin $75 \mathrm{mg} / \mathrm{m}^{2}$ ) repeated every 21 days for 3 cycles then evaluated by CT-Scan and bone scan for those with metastatic disease and by clinical exam for those with locally advanced disease.

\subsection{Methods}

Blood samples were taken from healthy cohort, disease-free then from patients before beginning of treatment, 24 hours after the first cycle and 24 hours after the completion of the third cycle. Samples were centrifuged and serum was collected and Caspase-3 and Caspase-7 levels were calibrated by means of (ELISA) from Sunred (China) and catalogue number 201-12-2258 for Caspase-7 Kit and catalogue number 201-12-0970 for Caspase-3 Kit. 
Table 1. Characteristics of patients.

\begin{tabular}{ccc}
\hline Type & Number & Percentage \\
\hline Invasive ductal carcinoma & 55 & $91 \%$ \\
Invasive lobular carcinoma & 5 & $9 \%$ \\
Metastatic disease & 50 & $83 \%$ \\
Locally advanced & 10 & $17 \%$ \\
Hepatic metastasis & 25 & $41 \%$ \\
Pulmonary mrtastasis & 22 & $36 \%$ \\
Skin metastasis & 3 & $5 \%$ \\
ER+ & 36 & $60 \%$ \\
PR+ & 42 & $70 \%$ \\
Her-2+ & 35 & $58 \%$
\end{tabular}

\subsection{Biostatistics}

Correlation between parameter was assessed by Spearman's test, while Mann-Whitney test was employed to compare between means. To assess the relation between types of response and Caspase-3/7 levels after 24 hours of the first chemotherapy, Qui square was used. Statistical significance was assigned to $P$ value less than 0.05 .

\section{Results}

Of the 60 patients included in the study, the disease progressed in 21 patients (35\%) with less than 0.5 fold increase in Caspase-3 concentration after 24 hours of the first cycle. 7 patients (11\%) with Caspase-3 concentration fold increase between 0.5 - 0.9 showed stable disease while the remaining 22 patients (54\%) showed partial response with Caspase-3 fold increase between 1 - 1.6 fold increase. In the other hand, the 10 complete responders showed a fold increase between $(1.7$ - 3), 24 hours after the completion of the first cycle as illustrated in Table 2 and concentration overtime are seen in Figure 1.

To evaluate the statistical relation between Caspase-3 fold increase (before and 24 hours after the first cycle) and response to treatment, Chi square was employed showing P value 0.002. Also, Caspase-3 level was compared between patient group and control group showed a mean Caspase-3 level of $2.3 \mathrm{ng} / \mathrm{ml}$ and $2 \mathrm{ng} / \mathrm{ml}$ respectively. The Mann-Whitney test was used to compare Caspase-3 concentrations in both groups (patients and control) showing a substantial difference and $\mathrm{P}$ value of 0.0001 . The same former statistical method was used also to compare Caspase- 3 concentration before treatment (mean of $2.3 \mathrm{ng} / \mathrm{ml}$ ), 24 hours after the first cycle (mean of $3.5 \mathrm{ng} / \mathrm{ml}$ ) and after the end of the third cycle (mean of $3.13 \mathrm{ng} / \mathrm{ml}$ ) showed a statistical difference and $\mathrm{P}$ value of 0.0003 .

36 patient had Estrogen receptors positive disease (60\%), 25 patients of which showed both partial and complete response on treatment with $\mathrm{P}$ value of 0.005 meaning that there is a direct proportion between Estrogen receptor status (+) and response to treatment. In the other hand, Her-2 was positive in 35 patients, 12 of which showed response while 7 out of 25 with Her-2 (-) showed response with $\mathrm{P}$ value of 0.06 showing that there is no Her-2 status impact on response to treatment.

In a similar manner, Caspase-7 concentration was evaluated in 60 patients and the relation between fold increase and response is illustrated in Table 3 and concentration overtime in Figure 2.

Of the 60 patients included in the study, the disease progressed in 20 patients (34\%) with less than 0.5 fold increase in Caspase-7 concentration after 24 hours of the first cycle. 8 patients (13\%) with Caspase-7 concentration fold increase between 0.5 - 0.9 showed stable disease while the remaining 27 patients (45\%) showed partial response with Caspase-7 fold increase between 1 - 1.6 fold increase. In the other hand, the 8 complete responders showed a fold increase between (1.7 - 3), 24 hours after the completion of the first cycle as illustrated in Table 2.

To evaluate the statistical relation between Caspase-7 fold increase (before and 24 hours after the first cycle) and response to treatment, Chi square was employed showing P value 0.005. Also, Caspase-7 level was compared between patient group and control group showed a mean Caspase-3 level of $2.635 \mathrm{ng} / \mathrm{ml}$ and $2.995 \mathrm{ng} / \mathrm{ml}$ 
Table 2. The relation between Caspase- 3 concentration 24 hours after the $1^{\text {st }}$ cycle and type of response.

\begin{tabular}{cccc}
\hline Number of patients & Caspase- 3 fold increase & Type of response & Percentage \\
\hline 21 & $<0.5$ & Progression & 35 \\
7 & $0.5-0.9$ & Stable & 11 \\
22 & $1-1.6$ & Partial response & 37 \\
10 & $1.7-3$ & Complete response & 17 \\
\hline
\end{tabular}

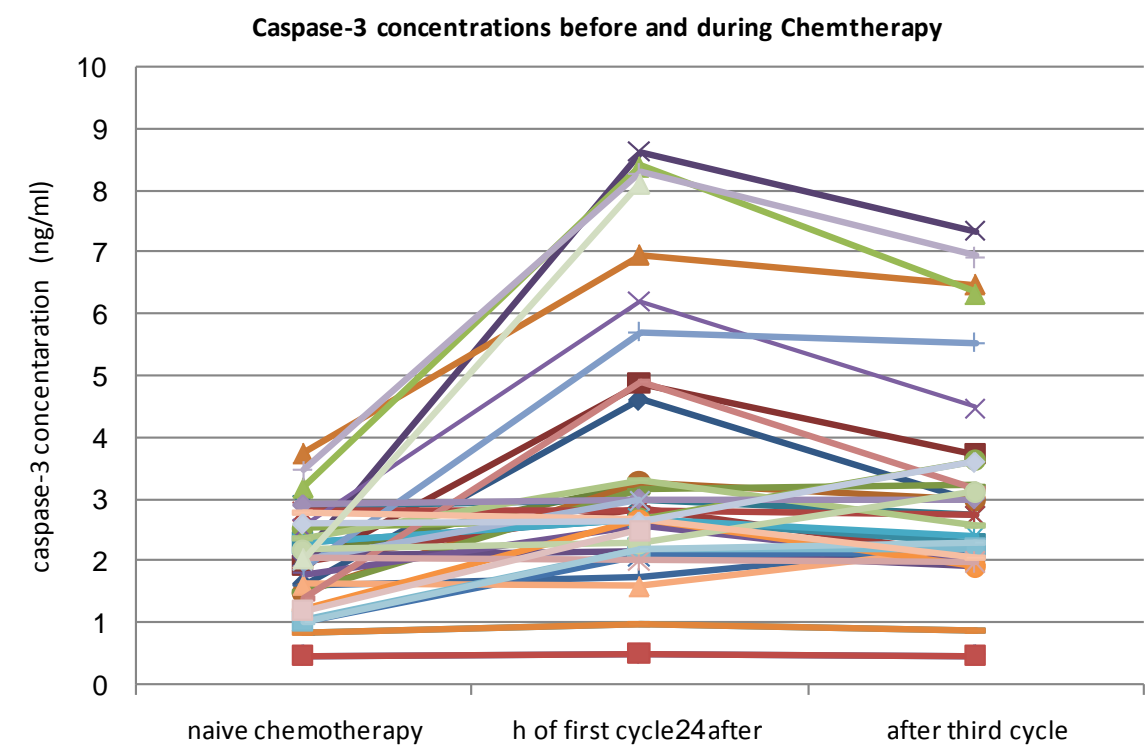

Figure 1. Caspase-3 concentrations in each patient before and during the chemotherapy.

Table 3. The relation between Caspase-7 concentration 24 hours after the $1^{\text {st }}$ cycle and type of response.

\begin{tabular}{cccc}
\hline Number of patients & Caspase-7 fold increase & Type of response & Percentage \\
\hline 20 & $<0.5$ & Progression & 34 \\
8 & $0.5-0.9$ & Stable & 43 \\
27 & $1-1.6$ & Partial response & 45 \\
5 & $1.7-3$ & Complete response & 8 \\
\hline
\end{tabular}

respectively. The Mann-Whitney test was used to compare Caspase-7 concentrations in both groups (patients and control) showing a substantial difference and $\mathrm{P}$ value of 0.0001 . The same former statistical method was used also to compare Caspase-7 concentration before treatment (mean of $2.635 \mathrm{ng} / \mathrm{ml}$ ), 24 hours after the first cycle (mean of $3.968 \mathrm{ng} / \mathrm{ml}$ ) and after the end of the third cycle (mean of $3.752 \mathrm{ng} / \mathrm{ml}$ ) showed no statistical difference and $\mathrm{P}$ value of 0.07 .

Regarding ER and Her-2 status, no relation was found between response and (ER, Her-2 status) with P value of 0.2 .

We studied the relation between Caspase-3 and Caspase-7 fold increase 24 hours after the $1^{\text {st }}$ cycle using Pearson correlation showed $r=0.796$ and $\mathrm{P}$ value 0.003 which confirm a strong relation between the two types of Caspases 3 and 7. Two responders are seen in Image 1 and Image 2 (hepatic metastasis and bone metastasis respectively).

\section{Discussion}

A failure to undergo apoptosis is widely believed to be a key event in cancer formation and progression [11] 


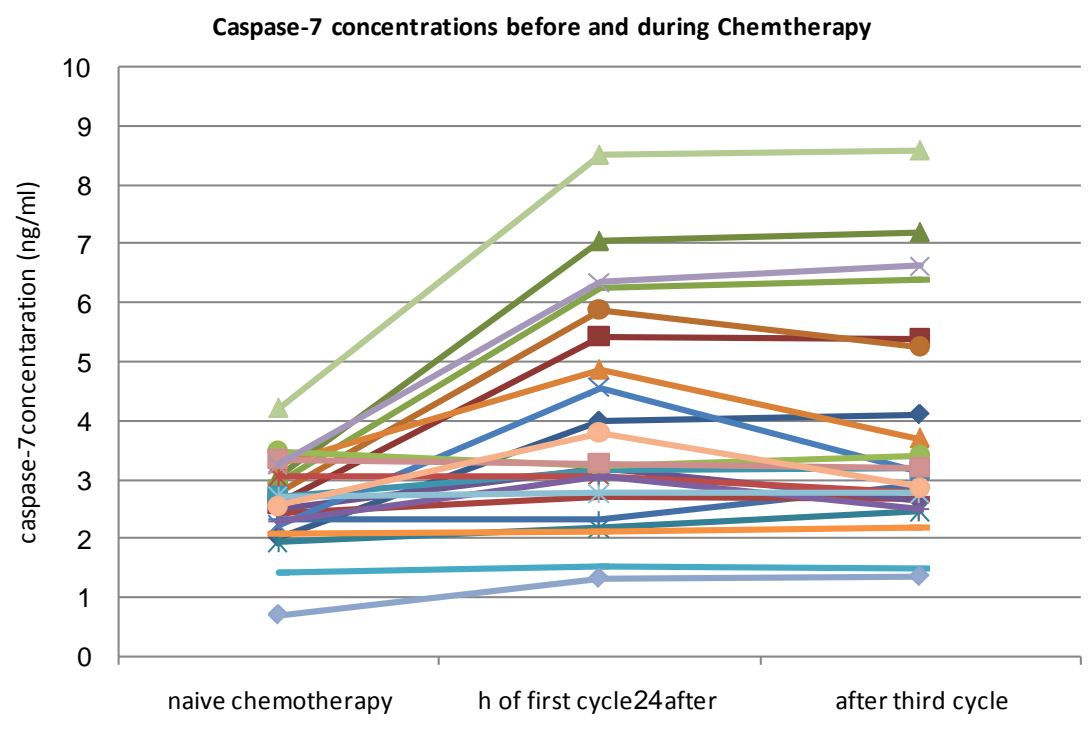

Figure 2. Caspase-7 concentrations in each patient before and during the chemotherapy.

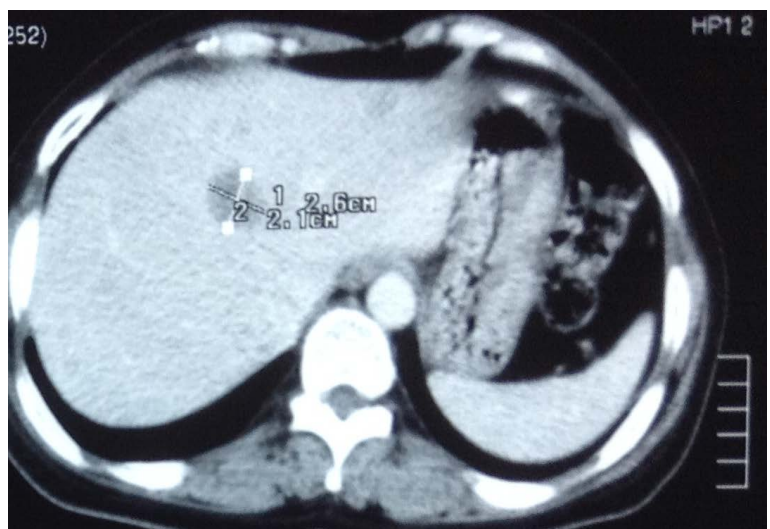

before

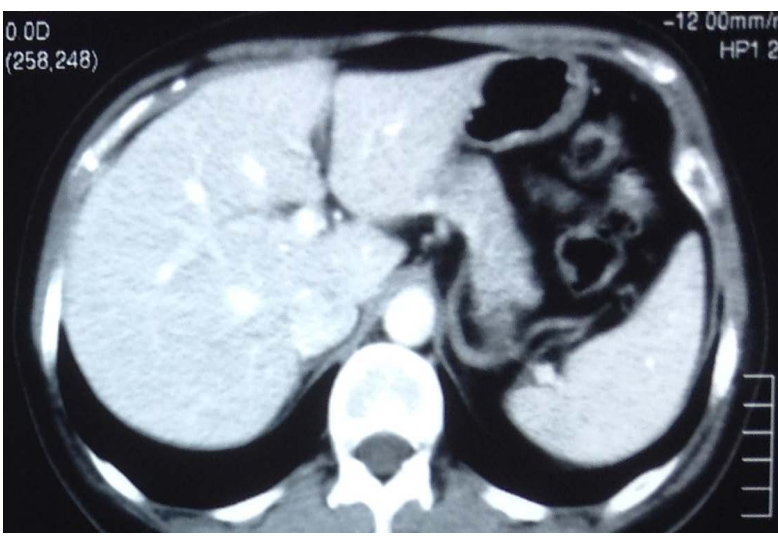

after

Image 1. A patient with hepatic metastasis with complete response.

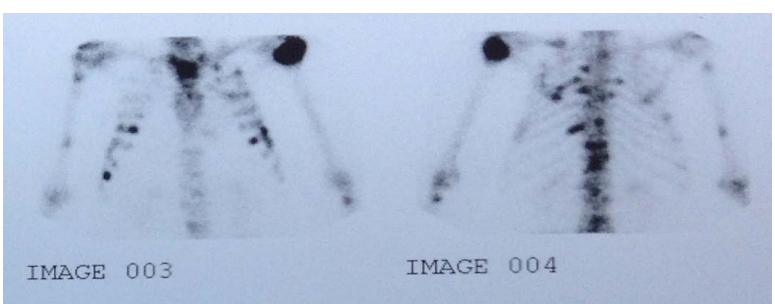

before

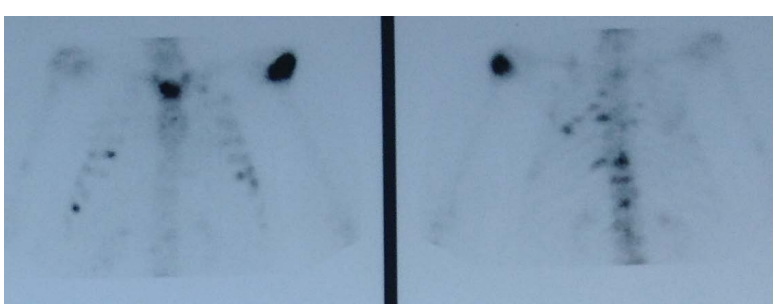

after

Image 2. A patient with bone metastasis with a major response.

[12]. Several studies on Caspase-3 lost MCF-7 showed resistance to chemotherapy while restoring Caspase-3 in those cells which showed regain of chemosensitivity [13]. As illustrated in Figure 3, Apoptosis has an intrinsic and pathway meeting at the same point called execution point where Caspase-3 is considered as the most important factor of execution. Caspase-3 in turn activates Caspase-7, therefore, elevation in Caspase-3 concentration will lead to a similar increase in Caspase-7 level.

In our study, we measured serum Caspase-3 and Caspase-7 levels in patients with both locally advanced and metastatic breast cancer to reveal the relation between Caspase levels and response to chemotherapy protocol 


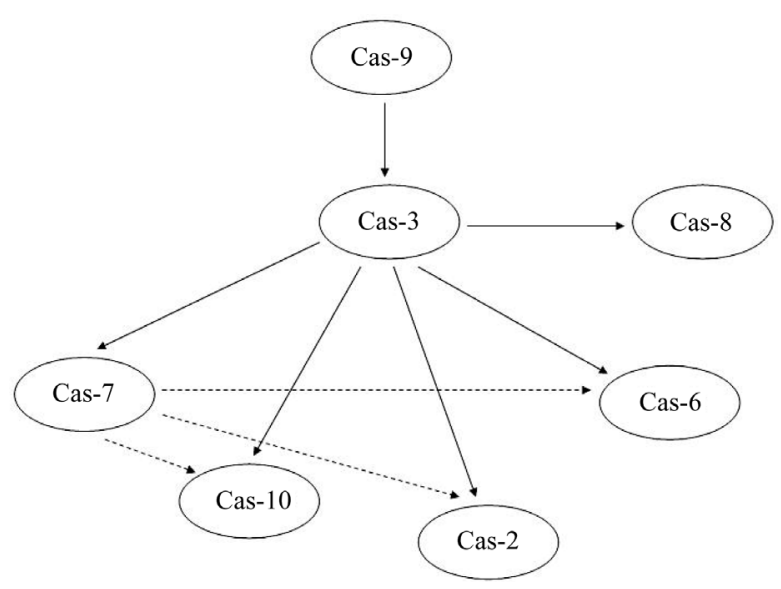

Figure 3. Illustrates the relation between Caspase-3 and different types of Caspases (Cas = Caspase).

(Docetaxel + Doxorubicin). In neoadjuvant and metastatic setting, we do not know which patient will respond to chemotherapy. Response to chemotherapy is considered a good prognostic factor and may predict a long progression free survival period [14]. Our study showed that Caspase-3, 7 elevation especially 24 hours after the first cycle is the most important predictor of response on the short term, and there is a direct proportion between fold increase and degree of clinical and radiologic response with $P$ value of 0.0003 .

Death of tumor cells generates detectable protein products in the patient's circulation, which may be used for cancer diagnostics and/or monitoring of therapy efficacy [15]. Apoptosis is a form of regulated cell death that is characterized by specific structural changes, mediated by proteases of the Caspase family [16]. Epirubicin/ 5-fluorouracil treatment led to a heterogeneous response with regard to cell death mode [17] [18]. In preclinical models, studies have shown an increase of apoptotic proteins 1 - 3 days after chemotherapy [19]-[21]. In our study and in a similar way, Caspase-3, 7 levels are elevated after 24 hours after the first cycle with a serum level decreasing over time to reach a lower concentration after the $3^{\text {rd }}$ cycle which could be attributed to decrease in tumor volume and consequently apoptotic proteins in responders, however, low level of Caspases after the first cycle accompanied with lower levels over time revealed a non responsive disease. This finding may help researchers and clinicians to best tailor the treatment of locally advanced and metastatic breast cancer and to predict the chemoresistant patients from the very beginning. But, if we find low levels after the first cycle, are we able to change chemotherapeutic protocol? It is still a hard question to answer so far, because other factors may affect response to chemotherapy such as ER status, Her-2 status and nodal status.

Regarding chemotherapy, Taxanes induce mitotic catastrophe, characterized by the occurrence of aberrant mitosis followed by cell division. Mitotic catastrophe is not a cell death mode, but will trigger cell death, either by apoptosis or by nonapoptotic mechanisms [22]-[24] and our study is supporting this concept through elevation of Caspase-3, 7 in vivo after treatment with Docetaxel in combination with Doxorubicin. Therefore, we can conclude that Caspase-3, 7 level in serum could be used as a predictive factor of response in patients with measurable disease breast cancer only when measured 24 hours after the $1^{\text {st }}$ cycle, however, further studies with other protocols are warranted to tailor our treatment in a better way.

\section{Disclosure}

All authors declare no conflict of interest.

\section{References}

[1] Burstein Harold, J., Harris, J.R. and Monica, M. (2008) Malignant Tumors of the Breast. In: Devita, V.T., Lawrence, T.S. and Rosenberg, S.A., Eds., Cancer Principles \& Practice of Oncology, 2, Williams and Wilkins, Wolters Kluwer Lippincott, 1606-1654.

[2] Shahla, M. (2000) Assessment of Prognostic Factors in Breast Fine-Needle Aspirates. American Journal of Clinical Pathology, 113, S84-S96. 
[3] Gilmore, A.P., Metcalfe, A.M., Romer, L.H. and Streuli, C.H. (2000) Integrin-Mediated Survival Signals Regulate the Apoptotic Functions of Bax through Its Conformation and Subcellular Localization. The Journal of Cell Biology, 149, 431-445. http://dx.doi.org/10.1083/jcb.149.2.431

[4] Lipponen, P. and Aaltomaa, S. (1994) Apoptosis in Bladder Cancer as Related to Standard Prognostic Factors and Prognosis. The Journal of Pathology, 73, 333-339. http://dx.doi.org/10.1002/path.1711730408

[5] Stennicke, H.R. and Salvesen, G.S. (1998) Properties of the Caspases. Biochimica et Biophysica Acta, 1387, 17-31. http://dx.doi.org/10.1016/S0167-4838(98)00133-2

[6] Thornberry, N.A. and Lazebnik, Y. (1998) Caspases: Enemies within. Science, 281, 1312-1316. http://dx.doi.org/10.1126/science.281.5381.1312

[7] Keane, M.M., Ettenberg, S.A., Nau, M.M., Russell, E.K. and Lipkowitz, S. (1999) Chemotherapy Augments TRAILInduced Apoptosis in Breast Cell Lines. Cancer Research, 59, 734-741.

[8] Bellarosa, D., Ciucci, A., Bullo, A., Nardelli, F., Manzini, S., Maggi, C. A. and Goso, C. (2001) Apoptotic Events in a Human Ovarian Cancer Cell Line Exposed to Anthracyclines. Journal of Pharmacology and Experimental Therapeutics, 296, 276-283.

[9] Kottke, T.J., Blajeski, A.L., Martins, M., Mesner Jr., P.W., Davidson, N.E., Earnshaws, W.C., Armstrong, D.K. and Kaufmann, S.H. (1999) Comparison of Paclitaxel-, 5-Fluoro-2-deoxyuridine- and Epidermal Growth Factor (EGF)-Induced Apoptosis. The Journal of Biological Chemistry, 274, 15927-15936. http://dx.doi.org/10.1074/jbc.274.22.15927

[10] Suzuki, A., Kawabata, T. and Kato, M. (1998) Necessity of Interleukin-1 $\beta$ Converting Enzyme Cascade in TaxotereInitiated Death Signaling. European Journal of Pharmacology, 343, 87-92. http://dx.doi.org/10.1016/S0014-2999(97)01520-3

[11] Kerr, J.F., Winterford, C.M. and Harmon B.V. (1994) Apoptosis. Its Significance in Cancer and Cancer Therapy. Cancer, 73, 2013-2026. http://dx.doi.org/10.1002/1097-0142(19940415)73:8<2013::AID-CNCR2820730802>3.0.CO;2-J

[12] Evan, G.I. and Vousden, K.H. (2001) Proliferation, Cell Cycle and Apoptosis in Cancer. Nature, 411, 342-348. http://dx.doi.org/10.1038/35077213

[13] Yang, X.-H., Sladek, T.L., Liu, X., Butler, B.R., Froelich, C.J. and Thor, A.D. (2001) Reconstitution of Caspase 3 Sensitizes MCF-7 Breast Cancer Cells to Doxorubicin- and Etoposide-Induced Apoptosis. Cancer Research, 61, 348-354.

[14] Scholl, S.M., Beuzeboc, P., Harris, A.L., et al. (1998) Is Primary Chemotherapy Useful for All Patients with Primary Invasive Breast Cancer? Recent results. Cancer Research, 152, 217-226. http://dx.doi.org/10.1007/978-3-642-45769-2_21

[15] Holdenrieder, S. and Stieber, P. (2004) Apoptotic Markers in Cancer. Clinical Biochemistry, 37, 605-617. http://dx.doi.org/10.1016/j.clinbiochem.2004.05.003

[16] Degterev, A. and Yuan, J. (2008) Expansion and Evolution of Cell Death Programmes. Nature Reviews Molecular Cell Biology, 9, 378-390. http://dx.doi.org/10.1038/nrm2393

[17] Leers, M.P., Kölgen, W., Björklund, V., Bergman, T., et al. (1999) Immunocytochemical Detection and Mapping of a Cytokeratin 18 Neoepitope Exposed during Early Apoptosis. The Journal of Pathology, 187, 567-572. http://dx.doi.org/10.1002/(SICI)1096-9896(199904)187:5<567::AID-PATH288>3.0.CO;2-J

[18] Olofsson, M.H., Ueno, T., Pan, Y., Xu, R., Cai, F., et al. (2007) Cytokeratin-18 Is a Useful Serum Biomarker for Early Determination of Response of Breast Carcinomas to Chemotherapy. Clinical Cancer Research, 13, 3198-3206. http://dx.doi.org/10.1158/1078-0432.CCR-07-0009

[19] Meyn, R.E., Stephens, L.C., Hunter, N.R. and Milas, L. (1995) Apoptosis in Murine Tumors Treated with Chemotherapy Agents. Anticancer Drugs, 6, 443-450. http://dx.doi.org/10.1097/00001813-199506000-00013

[20] Ellis, P.A., Smith, I.E., McCarthy, K., et al. (1997) Preoperative Chemotherapy Induces Apoptosis in Early Breast Cancer. Lancet, 349, 849. http://dx.doi.org/10.1016/S0140-6736(05)61752-7

[21] Green, A.M. and Steinmetz, N.D. (2002) Monitoring Apoptosis in Real Time. Cancer Journal, 8, 82-92. http://dx.doi.org/10.1097/00130404-200203000-00002

[22] Morse, D.L., Gray, H., Payne, C.M. and Gillies, R.J. (2005) Docetaxel Induces Cell Death through Mitotic Catastrophe in Human Breast Cancer Cells. Molecular Cancer Therapeutics, 4, 1495-504. http://dx.doi.org/10.1158/1535-7163.MCT-05-0130

[23] Jordan, M.A.,Wendell, K., Gardiner, S., Derry, W.B., et al. (1996) Mitotic Block Induced in HeLa Cells by Low Concentrations of Paclitaxel (Taxol) Results in Abnormal Mitotic Exit and Apoptotic Cell Death. Cancer Research, 56, 816-825.

[24] Blajeski, A.L., Kottke, T.J. and Kaufmann, S.H. (2001) A Multistep Model for Paclitaxel-Induced Apoptosis in Human Breast Cancer Cell Lines. Experimental Cell Research, 270, 277-288. http://dx.doi.org/10.1006/excr.2001.5349 